\title{
Editoria]
}

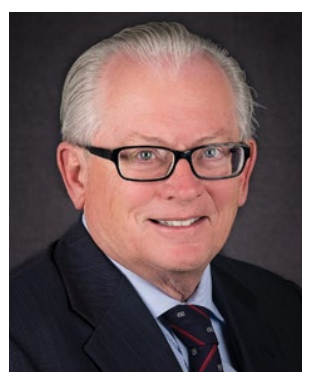

Stephen M. Stahl, MD, PhD

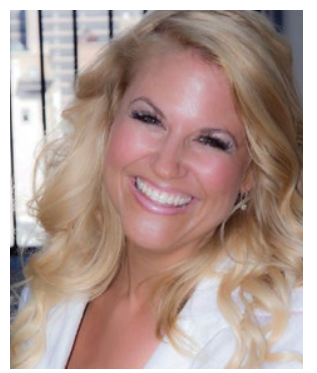

Sabrina Segal, PhD
To comment on this

editorial or other topics

\section{of interest:}

henry.nasrallah

@currentpsychiatry.com

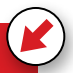

He has received research and/or grant support from Acadia, Avanir, Braeburn, Lilly, Intra-Cellular, Ironshore, International Society for the Study of Women's Sexual Health, Neurocrine, Otsuka, Shire, Sunovion, and TMS NeuroHealth Centers. Dr. Segal reports no financial relationships with any companies whose products are mentioned in this article, or with manufacturers of competing products.

doi: 10.12788/cp.0199 the tricyclic antidepressants, as well as major and minor tranquilizers, such as chlorpromazine and benzodiazepines, only to fizzle out in the 1980s. By the 1990s, the second generation of innovation in psychopharmacology was in full swing, with the "new" serotonin selective reuptake inhibitors and serotonin-norepinephrine reuptake inhibitors for depression, and the "atypical" antipsychotics for schizophrenia. However, soon after the turn of the century, pessimism for psychiatric therapeutics crept in again, and "big Pharma" abandoned their psychopharmacology programs in favor of other therapeutic areas. Surprisingly, the current "green shoots" of new ideas sprouting in our field today have not come from traditional big Pharma returning to psychiatry, but largely from small, innovative companies. These new entrepreneurial small pharmas and biotechs have found several new therapeutic targets. Furthermore, current innovation in psychopharmacology is increasingly following a paradigm shift away from DSM-5 disorders and instead to domains or symptoms of psychopathology that cut across numerous psychiatric conditions (transdiagnostic model).

So, what are the new therapeutic mechanisms of this current third generation of innovation in 
Figure 1

Trace amine-associated receptor 1 (TAAR1) agonists reduce presynaptic dopamine synthesis without the need to block postsynaptic dopamine $D 2$ receptors to treat psychosis

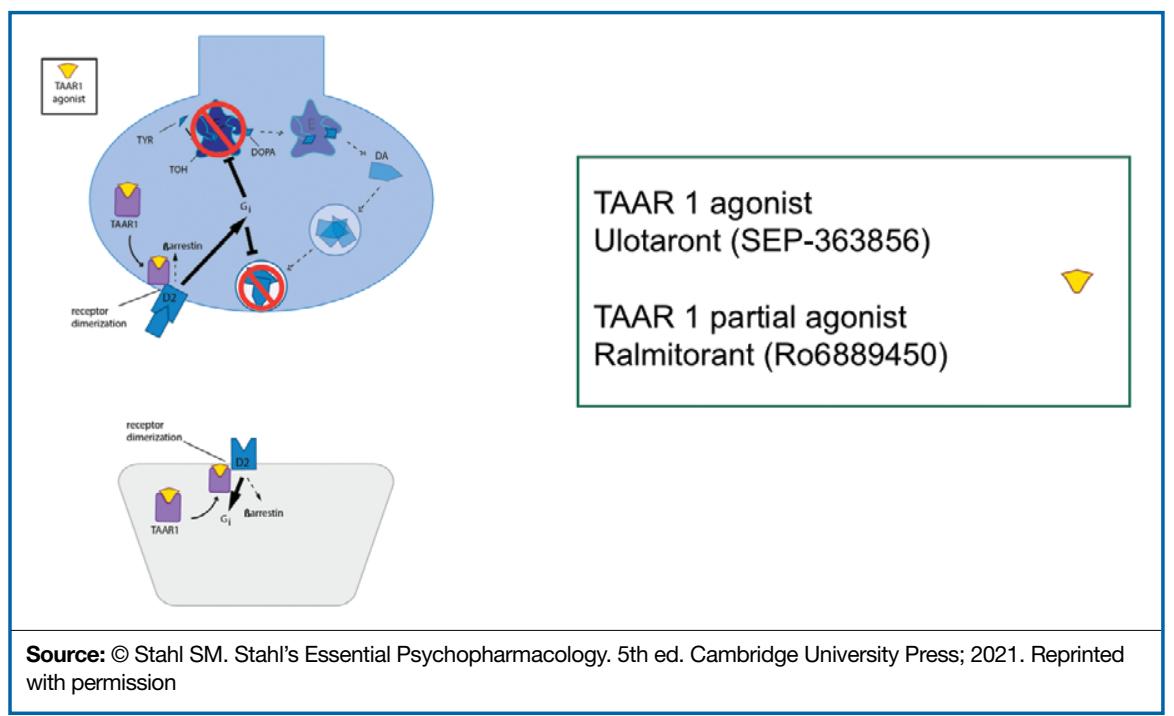

Figure 2

Upstream acetylcholine stimulation of dopamine release reduced by presynaptic M4 activator/agonist without the need to block postsynaptic dopamine D2 receptors to treat psychosis

\section{Kar-XT}

M1/M4 Central Muscarinic Agonist (M4 activator)

\section{(Xanomeline}

Combined with the peripherally acting anticholinergic trospium)

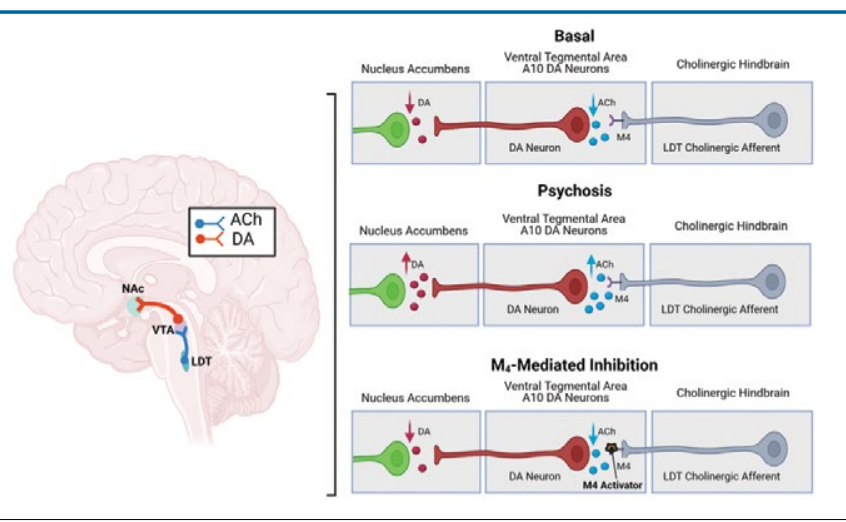

Source: (C) Stahl SM. Stahl's Essential Psychopharmacology. 5th ed. Cambridge University Press; 2021. Reprinted with permission

psychopharmacology? Not all of these can be discussed here, but 2 examples of new approaches to psychosis deserve special mention because, for the first time in 70 years, they turn away from blocking postsynaptic dopamine D2 receptors to treat psychosis and instead stimulate receptors in other neurotransmitter systems that are linked to dopamine neurons in a network "upstream." That is, trace amine-associated receptor 1 (TAAR1) agonists target the pre-synaptic dopamine neuron, where dopamine synthesis and release are too high in psychosis, and cause dopamine
Editorial Staff

EDITOR Jeff Bauer

SENIOR EDITOR Sathya Achia Abraham ASSISTANT EDITOR Matthew Wyles WEB EDITOR Christina Manago

Art \& Production Staff CREATIVE DIRECTOR Louise Koenig ART DIRECTOR Pat Fopma

DIRECTOR, JOURNAL MANUFACTURING Michael Wendt

PRODUCTION MANAGER Donna Pituras

Publishing Staff

PUBLISHER Sharon Finch

DIRECTOR EBUSINESS DEVELOPMENT Alison Paton

SENIOR DIRECTOR OF SALES

Tim LaPella

Editor-in-Chief Emeritus

James Randolph Hillard, MD

Frontline Medical Communications VP, SALES Mike Guire

VP, DIGITAL CONTENT \& STRATEGY Amy Pfeiffer

PRESIDENT, CUSTOM SOLUTIONS JoAnn Wahl

CIRCULATION DIRECTOR Jared Sonners

In affiliation with Global Academy for Medical Education, LLC

PRESIDENT David J. Small, MBA

\section{FRONTLINE MLedge}

7 Century Drive, Suite 302

Parsippany, NJ 07054

Tel: (973) 206-3434

Fax: (973) 206-9378

www.frontlinemedcom.com

Subscription Inquiries:

subscriptions@mdedge.com

Published through an educational partnership with

\section{l(C CINCINNATI}




\section{Figure 3}

Two types of GABA-A-mediated inhibition: Phasic (benzodiazepine sensitive) and tonic (benzodiazepine insensitive) with both sensitive to neuroactive steroids

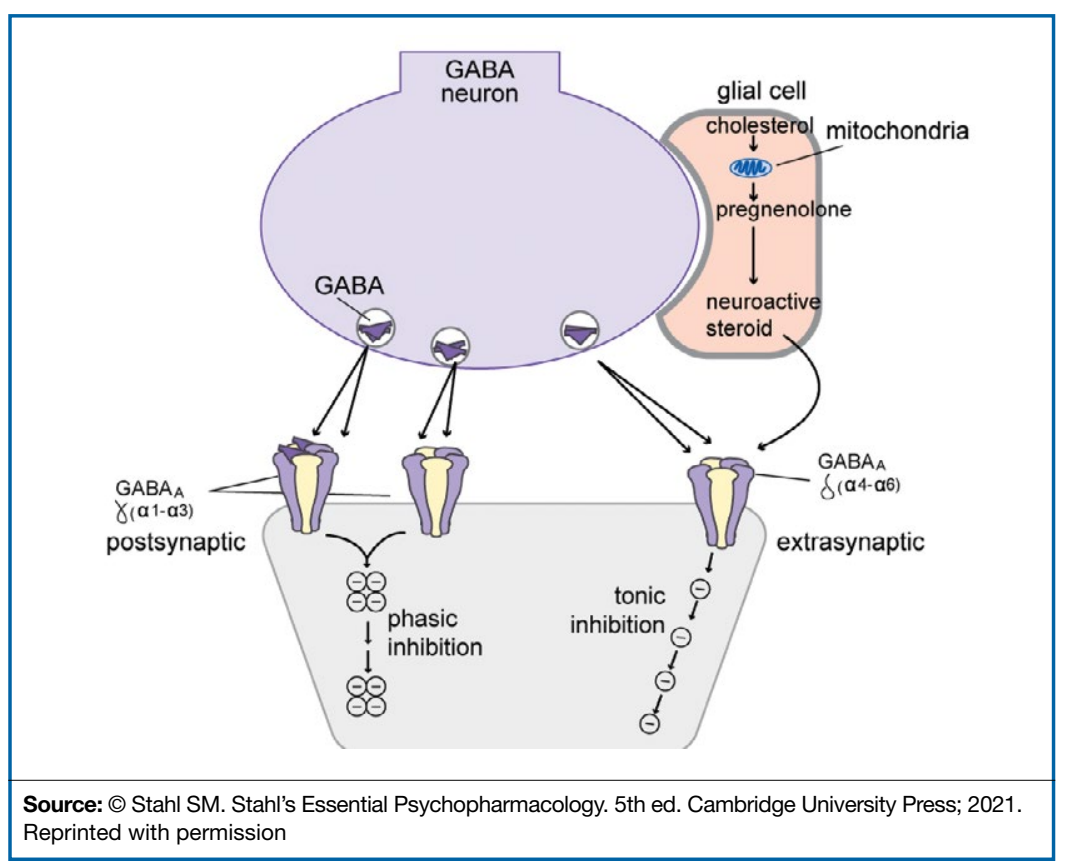

Source: $@$ Stahl SM. Stahl's
Reprinted with permission

\section{Table 1}

\section{Examples of new drug mechanisms in psychopharmacology}

Trace amine-associated receptor 1 (TAAR1) agonists for schizophrenia

Cholinergic agonists at central muscarinic M1 and M4 receptors for schizophrenia and psychosis in Alzheimer's dementia

Novel, orally available $N$-methylD-aspartate (NMDA) antagonist dextromethorphan combination with either quinidine or bupropion for rapid-onset, treatment-resistant unipolar depression and for agitation in Alzheimer's dementia

Novel, orally available NMDA antagonist esmethadone for rapid-onset, potentially treatment-resistant depression

Neuroactive steroids as novel GABA-A positive allosteric modulators for rapidonset antidepressant action in unipolar depression and postpartum depression

\section{Table 2}

\section{Examples of novel potential indications for approved drugs in psychopharmacology}

Lumateperone for bipolar depression and augmentation of SSRIs/SNRIs in unipolar depression

Cariprazine for augmentation of SSRIs/SNRIs in unipolar major depressive disorder

Brexpiprazole for agitation in Alzheimer's dementia and in posttraumatic stress disorder

Pimavanserin for negative symptoms of schizophrenia and for dementia-related psychosis

SNRIs: serotonin-norepinephrine reuptake inhibitors; SSRIs: selective serotonin reuptake inhibitors

Another major area of innovation in psychopharmacology worthy of emphasis is the rapid induction of neurogenesis that is associated with rapid reduction in the symptoms of depression, even when many conventional treatments have failed. Blockade of N-methyl-Daspartate (NMDA) glutamate receptors is associated with rapid neurogenesis continued on page 25 
Guest Editorial

continued from page 8

that may hypothetically drive rapid recovery from depression. ${ }^{1}$ Proof of this concept was first shown with intravenous ketamine, and then intranasal esketamine, and now the oral NMDA antagonists dextromethorphan (combined with either bupropion or quinidine) and esmethadone (Table 1, page 8). ${ }^{1}$ Interestingly, this same mechanism may lead to a novel treatment of agitation in Alzheimer's dementia as well. ${ }^{1}$

Yet another mechanism of potentially rapid onset antidepressant action is that of the novel agents known as neuroactive steroids that have a novel action at gamma aminobutyric acid $\mathrm{A}$ (GABA-A) receptors that are not sensitive to benzodiazepines (as well as those that are) (Table 1 and Figure 3, page 8). ${ }^{1}$ Finally, psychedelic drugs that target serotonin receptors such as psilocybin and 3,4-methylenedioxymethamphetamine (MDMA, "ecstasy") seem to also have rapid onset of both neurogenesis and antidepressant action. ${ }^{1}$ The list of innovations goes on and on, and also includes many novel potential indications for already approved agents (Table 2, page 8 ). Hopefully, these tables listing new therapeutic targets for psychiatric disorders as well as the discussion here provide the reader with a glimpse into the excitement and innovations afoot in this third generation of drug development in psychiatry.

The future of psychopharmacology is clearly going to be amazing.

\section{Reference}

1. Stahl SM. Stahl's Essential Psychopharmacology. 5th ed. Cambridge University Press; 2021.
This third generation of innovation in psychopharmacology focuses on new therapeutic mechanisms 